\title{
First Documented Study of Mycoplasma Wenyonii of Cattle in Iraq
}

\author{
Basima. A ${ }^{1}$, Baraa. $A^{2}$ \\ ${ }^{1}$ Department of Internal and Preventive Medicine, College of Veterinary Medicine, University of Mosul, Mosul-Iraq \\ ${ }^{2}$ Nineveh Agricultural Office, Application Studies Laboratory. Mosul -Iraq
}

\begin{abstract}
Mycoplasma wenyonii was studied by PCR and staining blood smears in twelve local breed cattle brought from different farms around Mosul city for examination in teaching hospital of Mosul University. Clinical signs and hematological parameters of all tested animals were compromised with data of another twelve local breed healthy cattle. Clinical sings of hind limb edema, pyrexia, painful swollen udders, pre-femoral and mammary lymph nodes enlargement with milk drop were noticed in dairy cows. Scrotal edema was found to be significantly associated with the infection in calves. Epi-erythrocytic organisms were seen on traditional - Wright's stained thick blood films and fluorescence microscopy techniques, acridine orange (AO) staining of thin blood films. Hematological examination revealed a regenerative anemia with elevation of WBC counts of infected cattle. Blood samples were submitted to the Animal Health and Veterinary Laboratory Agency, UK, to confirm diagnosis. Mycoplasma wenyonii (MW 599)-specific DNA was detected by PCR and Denaturing Gradient Gel Electrophoresis (DGGE) in five samples. This is the first document for detection of Mycoplasma wenyonii in cattle from Iraq.
\end{abstract}

Keywords: Cattle, Mycoplasma wenyonii, PCR/ DGGE, Iraq.

\section{Introduction}

Mycoplasma wenyonii is a member of the haemomycoplasmas, a group of haemotropic bacteria, which are found in close association with mammalian erythrocyte membranes. Mycoplasma wenyonii is common in cattle worldwide. Formerly known as Eperythrozoon wenyonii, it has been recently been reclassified to the Mycoplasma genus based on analysis of the 16S rRNA [1]. Mycoplasma wenyonii is an epicellular prokaryote found in cocci, ring, and rod shapes that parasitizes red blood cells of cattle. The organisms have a single-cell membrane and adhere to the red blood cell membrane, but are not intraerythrocytic [2, 3]. The mode of transmission of $M$. wenyonii is currently unknown, but most likely results from mechanical transmission by blood-sucking arthropods, direct contact, and iatrogenic transmission. The majority of cattle infected with $M$. wenyonii do not develop clinical signs. A clinical illness is rare and seen only when concurrent illness results in immunosuppression. Clinical signs associated with infection include anemia, ill-thrift, fever, lymphadenopathy, depression, diarrhea, and decreased milk production [4].

Haemoplasmas have never been cultured in vitro. So, until recently, their detection was only possible with a subjective and insensitive microscopy test for blood smears but is not specific for $M$. wenyonii and can be difficult to interpret. McAuliffe et al., have described the use of PCR and denaturing gradient gel electrophoresis (DGGE) for the detection and differentiation of Mycoplasma species [5, 6]. DGGE can be used on blood samples as a rapid and specific test for $M$. wenyonii and can also be used as a screening test for other blood borne pathogens [7]. However M. wenyonii has been recently reported in cattle of Iraq according to the microscopic examination of blood smears of anemic cattle during the first outbreak in 2011[8].
The objectives of this study were, firstly to confirm that structures observed on erythrocytes of anemic cattle by blood smear examination is $M$. wenyonii by molecular analysis, and secondly to determine if it is a newly observed organism which may be the cause of outbreaks of recumbence, hind limb edema, udder swelling and scrotal edema in cattle herds at various locations across Mosul-Iraq in recent years.

\section{Materials and Methods}

Twelve local breed cattle (six calves of 11 to 15 months of age and six dairy cows 2-7 years old) were brought from different farms around Mosul city to the Veterinary Teaching Hospital at Veterinary Medicine College of Mosul University, Mosul Iraq, and the calves were suffering of poor appetite, fever, tachycardia, tachypnea, emaciation, exhaustion, anemia, hind limbs and scrotal edema. Where dairy cows showed clinical signs of hind limbs and udder edema, pyrexia, pre-femoral and mammary lymph nodes enlargement with milk drop. Some of the cattle were treated at local veterinary clinics with Imidocarb dipropionate (3mg/kg/day for 2 days) or Oxytetracyclin (20 mg/ kg for 3 days) by intramuscular injections. The clinical signs and hematological parameters of all tested cattle were recorded. Another twelve cattle (Six calves and six dairy cows) were clinically normal and negative to hemomycoplasma in blood smears and then by PCR/ (DGGE) which served as uninfected controls.

As a material for this research, whole blood with EDTA and peripheral blood smears have been used. Two blood smears were prepared immediately after each blood collection. Thick blood smears were made and stained in Wright's -staining solution. Light microscopy was used to look for the presence of $M$. wenyonii on the erythrocyte surface. Also the fluorescence microscopy (BX51 Olympus U-RFL-T-Japan) was used to look for the microbes by mixing a drop of infected blood with acridine orange solution $(0.1 \mathrm{mg} / \mathrm{mL})$. 


\section{International Journal of Science and Research (IJSR) \\ ISSN (Online): 2319-7064}

Index Copernicus Value (2013): 6.14 | Impact Factor (2014): 5.611

Then, thin smears were made and examined under 100X [9]. Parasitaemia was confirmed on blood smears of all cattle showed clinical signs; Positive results with Mycoplasma wenyonii infection were consedered if one infected erythrocyte was found in 200 observed RBC [10]. We determined the percentage of reticulocytes by mixing equal parts of the anticogulated blood with New methylene blue, allowing the mixture to incubate at room temperature for 10 minutes, and preparing air-dried blood films from the mixture; the reticulocytes per 1000 erythrocytes were counted [11].

PCR, Denaturing Gel Electrophoresis (DGGE) and sequencing were performed at the Animal Health and Veterinary Laboratory Agency (AHVLA), (Weybridge), Woodham Lane, Addlestone, UK, from twelve anticoagulated EDTA blood samples of animals showing clinical signs to confirm diagnosis. Total Genomic DNA was extracted from $100 \mu \mathrm{L}$ of each blood sample using a tissue DNA extraction kit (Sigma). Amplification of the V3 region of the 16S RNA gene was performed according to the method of as described previously [5], using universal bacterial primers GC-341F 50-CGC CCG CCG CGC GCG GCG GGC GGG GCG GGG GCA CGG GGG GCC TAC GGG AGG CAG CAG and 534R 50-ATTACC GCG GCT GCT GG. DGGE was performed using the Ingeny PhorU 2 _ 2 apparatus (GRI Molecular Biology, Essex, UK). Samples were loaded onto $10 \%$ polyacrylamide/bis (37.5:1) gels with linear denaturing gradients from $30-60 \%$ (where $100 \%$ is 7 $\mathrm{M}$ urea and $40 \%(\mathrm{v} / \mathrm{v})$ deionized form amide) in 1 _ TAE electrophoresis buffer (Severn Biotech Ltd., Worcestershire, UK). Electrophoresis was performed at $100 \mathrm{~V}$ at a temperature of $60 \mathrm{8C}$ for $18 \mathrm{~h}$. Gels were then stained with SBYR Gold (Cambridge ioScience, Cambridge shire, UK) in 1 - TAE for $30 \mathrm{~min}$ at room temperature and visualized under UV illumination. Almost full-length 16S rRNA genes were amplified from isolates using the 63F and 1387R [12] primers under the conditions described above. PCR products were cleaned up using a Qiagen QIAquick PCR purification kit and products were quantified by running on $2 \%$ agarose E-gels with a quantitative E-gel ladder (Invitrogen). 16S rDNA was sequenced in both the forward and reverse direction and sequencing reactions were performed using a DTCS Quick Start sequencing kit (Beckman Coulter) according to the manufacturer's instructions. Samples were ethanol precipitated and run on a Beckman Coulter CEQ8800 Sequencer. Contigs were assembled using the CAP Contig program in Bioedit. These sequences were aligned with the closest matches found in the Ribosomal Database Project with the ClustalW function of the BioEdit package. Neighbor joining phylogenetic trees were constructed with the Molecular Evolutionary Genetics Analysis package (MEGA Version 2.1) using unweighted pair group mean analysis (UPGMA), and the robustness of the phylogeny was tested by bootstrap analysis with 500 iterations.

The arithmetic means $( \pm S D)$ of hematological parameters in different groups were calculated. Further analysis was done using analyses of variance (ANOVA) technique by SPSS statistical program and means were separated by Duncan's multiple range test. The level of significance was determined at $\mathrm{P}<0.05$.

\section{Results}

The main clinical signs of $M$. wenyonii infection in dairy cows in the present study were udder and hind limbs edema (Figure 1: A). Scrotal and hind limbs edema was associated with infection in bull calves (Figure 1: B).
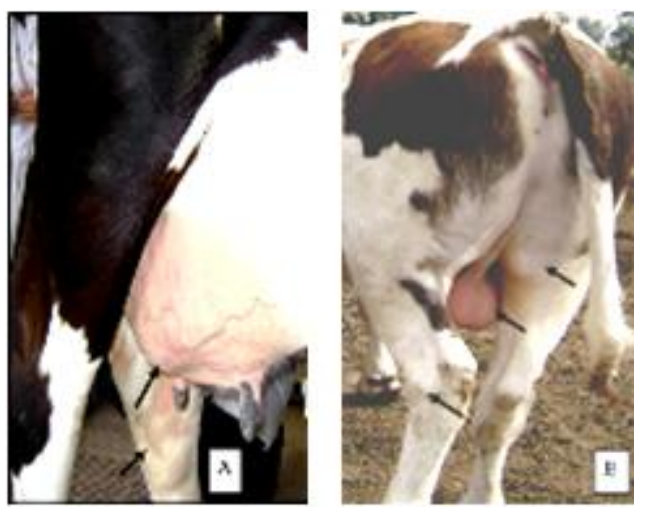

Figure 1: Udder and hind limb edema in cow (A), Scrotal and hind limb edema in a bull (B) testing positive for

Mycoplasma wenyonii on denaturing gradient gel electrophoresis.

Animals showed either acute illness characterized by recumbence, weakness, depression, pyrexia $\left(39.9 \pm 0.3^{\circ} \mathrm{C}\right.$ in dairy cows and $40.5 \pm 0.8^{\circ} \mathrm{C}$ in calves), tachycardia (96 \pm 8.3 beats/min in dairy cows and $132 \pm 11$ beats/min in calves) and tachypneia (38 \pm 5.6 breaths/min in dairy cows and $42 \pm 3.9$ breaths/min), or may demonstrate chronic illness characterize by weight loss, anorexia, emaciation, enlargement of prefemoral and supra-mammary lymph nodes.

Examination of peripheral blood smears revealed numerous small basophilic staining coccids structures $0.5-1 \mu \mathrm{m}$ in diameter with a number ranging from 1 to 90 organisms on the surface of the erythrocytes attached to cell membranes singularly or in clusters centered on a single membrane focus which caused different levels of RBC deformation, some erythrocytes were not infected (Figure 2).

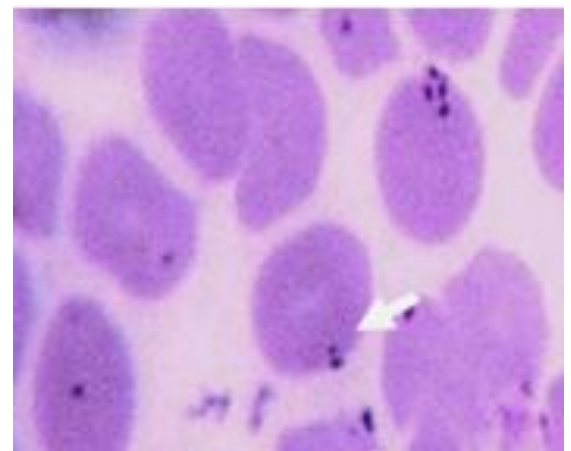

Figure 2: Light micrograph of Mycoplasma wenyonii. Note presences of numerous small basophilic structures under oil immersion 160X, Wright's stain.

Sometimes the organisms were observed free in the background; they were bigger and stained darker. The delicate fibrils of the organism could be seen even under a light microscope (Figure 3). 


\section{International Journal of Science and Research (IJSR) \\ ISSN (Online): 2319-7064 \\ Index Copernicus Value (2013): 6.14 | Impact Factor (2014): 5.611}

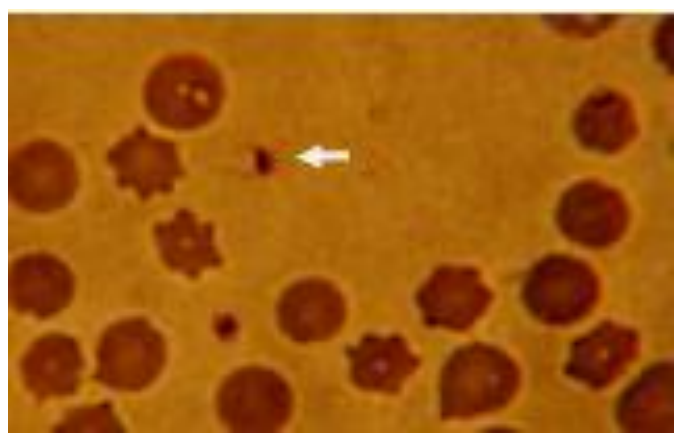

Figure 3: Note the delicate fibrils of free $M$. wenyonii in the background under the light microscope 100X. Wright's stain.

The hemomycoplasmas attached to the RBCs and platelets membrane surfaces in cases of high parasitemia. Erythrophagocytosis of the infected red blood cell were also seen in the blood smears of severely affected animals (Figure 4).

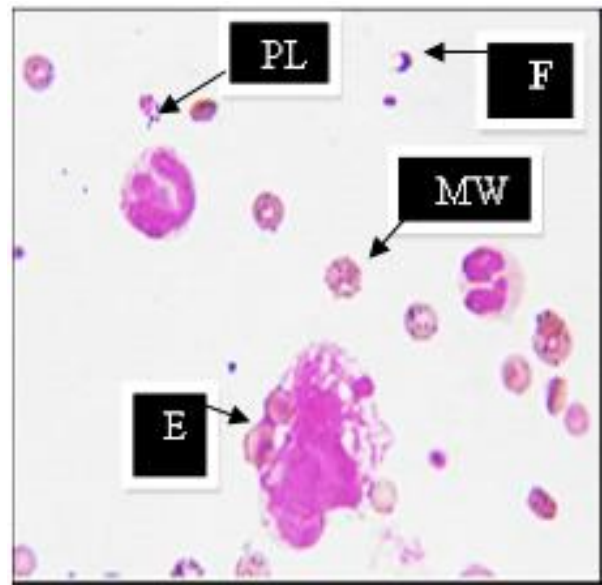

Figure 4: Wright's stain light micrograph of blood smear, $M$. wenyonii adhered on the surface of erythrocytes (MW) and on platelets (PL) with erythrophagocytosis of the infected RBC (E). Note the delicate fibrils of free $M$. wenyonii in the background (F) under oil immersion 100X.

In acridine orange-staind blood smears of infected cattle, numerous $M$.wenyonii as yellow to orange particles were seen on and between the erythrocytes (Figure 5). Acridine orange is significantly better than Wright's stain for detection of parasitemia, especially in cases with low parasitemia.

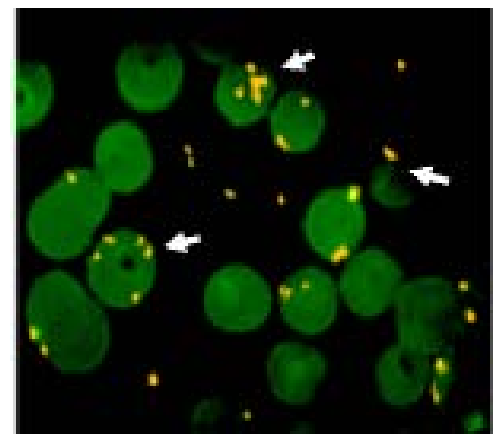

Figure 5: Mycoplasma wenyonii (MW) on and between the erythrocyte with high parasitemia in the peripheral blood smear stained with acridine orange under oil immersion 100X (fluorescence microscope).
On hematology, anemia had indicated by values of hemoglobin concentrations, erythrocytes counts and hematocrit in the clinically diseased cattle. The dairy cows had significantly lower hemoglobin (58.6 g/l \pm 6.1), erythrocytes $\left(3.51 \times 10^{12} / \mathrm{L} \pm 0.63\right)$ and hematocrit $(0.20 \mathrm{~L} / \mathrm{L}$ $\pm 0.07)$ levels than those in healthy control dairy cows, which exhibited values of $(105.6 \mathrm{~g} / \mathrm{l} \pm 12.8 \mathrm{~g} / \mathrm{l}),\left(8.6 \times 10^{12} / \mathrm{L} \pm 0.03\right)$ and $(0.34 \mathrm{~L} / \mathrm{L} \pm 0.04)$ respectively. In calves the hemoglobin concentration was $78.0 \mathrm{~g} / \mathrm{l} \pm 13.1$, erythrocytes counts was 2.8 $\mathrm{x} 10^{12} / \mathrm{L} \pm 0.25$ and hematocrit was $0.22 \mathrm{~L} / \mathrm{L} \pm 0.02$ in comparison with normal values in healthy calves. Macrocytic hypochromic and macrocytic normochromic anemia was revealed in infected dairy cows and calves respectively (Table 1). There was also a leukocytosis with mild neutrophilia (Table 2).

Table1: Hematological findings ((Mean \pm S.D.) of hemomycoplasma positive and negative groups

\begin{tabular}{|c|c|c|c|c|}
\hline Parameters & $\begin{array}{c}\text { Positive } \\
\text { cows } \\
(n=6)\end{array}$ & $\begin{array}{c}\text { Negative } \\
\text { cows } \\
(n=6)\end{array}$ & $\begin{array}{c}\text { Positive } \\
\text { calves }(n=6)\end{array}$ & $\begin{array}{c}\text { Negative } \\
\text { calves } \\
(n=6)\end{array}$ \\
\hline $\mathrm{Hb}(\mathrm{g} / \mathrm{L})$ & $58.6 \pm 6.1^{*}$ & $105.6 \pm 12.8$ & $78 . .0 \pm 13.1^{*}$ & $112.0 \pm 11.4$ \\
\hline $\mathrm{RBC}\left(\mathrm{x} 10^{12} / \mathrm{L}\right)$ & $3.51 \pm 0.63^{*}$ & $8.6 \pm 0.03$ & $2.8 \pm 0.25^{*}$ & $7.1 \pm 0.25$ \\
\hline $\mathrm{HCT}(\mathrm{L} / \mathrm{L})$ & $0.20 \pm 0.07^{*}$ & $0.34 \pm 0.04$ & $0.22 \pm 0.02^{*}$ & $0.32 \pm 0.01$ \\
\hline $\mathrm{MCV}(\mathrm{fl})$ & $57.1 \pm 4.1^{*}$ & $37.6 \pm 5.1$ & $78.5 \pm 1.6^{*}$ & $45.5 \pm 2.0$ \\
\hline $\mathrm{MCHC}(\mathrm{g} / \mathrm{L})$ & $293 \pm 11^{*}$ & $311 \pm 21$ & $354.5 \pm 23$ & $350 \pm 15$ \\
\hline Platelets $\left(\mathrm{x} 10^{9} / \mathrm{L}\right)$ & $327 \pm 25$ & $330 \pm 37$ & $350 \pm 45$ & $400 \pm 73$ \\
\hline
\end{tabular}

The statistics of each hemomycoplasma-positive group were compared with those of the negative group. $* P<0.05$; (vs. the negative group).

Table2: Hematological findings ((Mean \pm S.D.) of hemomycoplasma positive and negative groups

\begin{tabular}{|c|c|c|c|c|}
\hline Parameters & $\begin{array}{c}\text { Positive } \\
\text { cows } \\
(n=6)\end{array}$ & $\begin{array}{c}\text { Negative } \\
\text { cows } \\
(n=6)\end{array}$ & $\begin{array}{c}\text { Positive } \\
\text { calves } \\
(n=6)\end{array}$ & $\begin{array}{c}\text { Negative } \\
\text { Calves } \\
(n=6)\end{array}$ \\
\hline WBC $\left(\mathrm{x} 10^{6} / \mathrm{L}\right)$ & $13.8 \pm 1.6^{*}$ & $10.7 \pm 3.4$ & $13.4 \pm 1.8^{*}$ & $10.3 \pm 2.1$ \\
\hline Neutrophils(x10 $/ \mathrm{L})$ & $6.4 \pm 0.03^{*}$ & $3.3 \pm 0.06$ & $5.6 \pm 0.02^{*}$ & $1.2 \pm 0.01$ \\
\hline Lymphocytes $\left(\mathrm{x} 10^{9} / \mathrm{L}\right)$ & $6.8 \pm 0.02$ & $7.1 \pm 0.03$ & $7.0 \pm 0.5$ & $7.7 \pm 0.6$ \\
\hline Monocytes $\left(\mathrm{x} 10^{9} / \mathrm{L}\right)$ & $0.2 \pm 0.01$ & $0.3 \pm 0.07$ & $0.7 \pm 0.01$ & $0.8 \pm 0.02$ \\
\hline Eosinophil $\left(\mathrm{x} 10^{9} / \mathrm{L}\right)$ & $0.3 \pm 0.04$ & $0.8 \pm 0.03$ & $0.1 \pm 0.01$ & $0.6 \pm 0.08$ \\
\hline
\end{tabular}

The statistics of each hemomycoplasma-positive group were compared with those of the negative group. ${ }^{*} P<0.05$; (vs. the negative group).

Erythrocyte features included moderate anisocytosis and poikelocytosis, polychromasia, reticulocytosis, basophilic stippling, nucleated erythrocytes (NRBC) with presence of Howell-Jolly bodies and Heinz bodies (Figures 6- 9). The reticulocyte percentage was about $2-3 \%$ and the absolute reticulocyte concentration was about $27800 / \mathrm{L}$ in infected dairy cows and 40,200/L in calves on a new methylene blue stained slides in comparison with normal values $10,000 / \mathrm{L}$ in healthy cattle. About 5-10 NRBC/100WBC were counted with mostly metarubricytes and fewer polychromatophilic rubricytes. Low numbers of neutrophils exhibited mild toxic changes with cytoplasmic basophilia and Döhle bodies (Fig. 9B) (Table 3). 


\section{International Journal of Science and Research (IJSR) \\ ISSN (Online): 2319-7064}

Index Copernicus Value (2013): 6.14 | Impact Factor (2014): 5.611

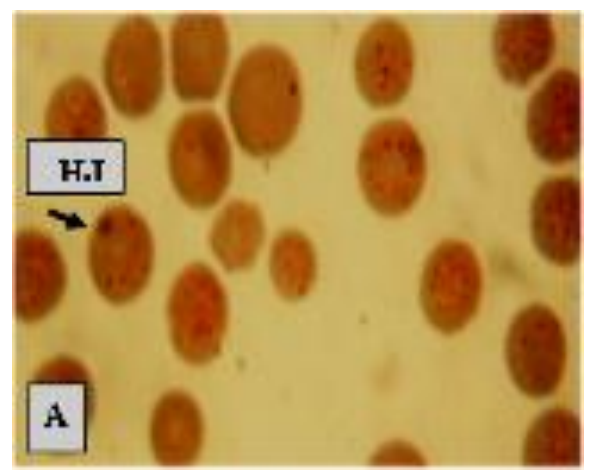

Figure 6(A): Wright's stain blood smear of anemic cow infected with Mycoplasma wenyonii, Note anisocytosis with Howell-Jolly bodies (HJ) under 160X.

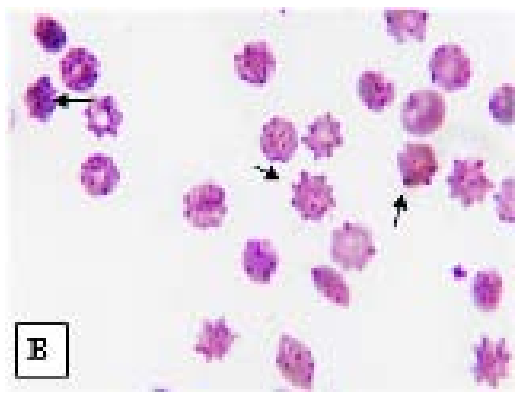

Figure 6(B): The infected erythrocytes have multiple punctate; bacillary, or ring forms and poikelocytosis under $100 X$.

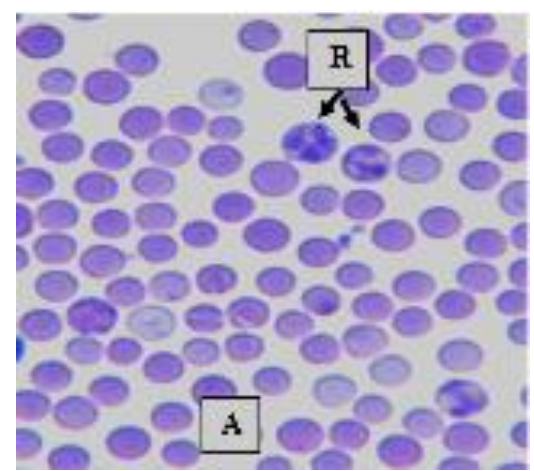

Figure 7(A): Blood smears from anemic calve with eperythrocytic haemomycoplasma organisms, Note the reticulocytosis (R) in New methylene blue stain.

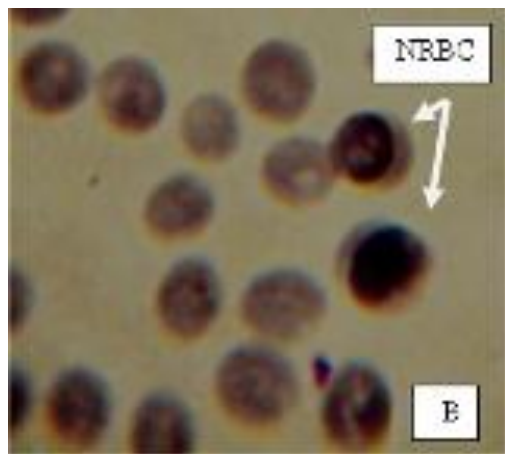

Figure 7(B): A nucleated erythrocyte (metarubricyte) is present in the upper right (NRBC) of blood smear. Wrightstain, under oil immersion 160X.

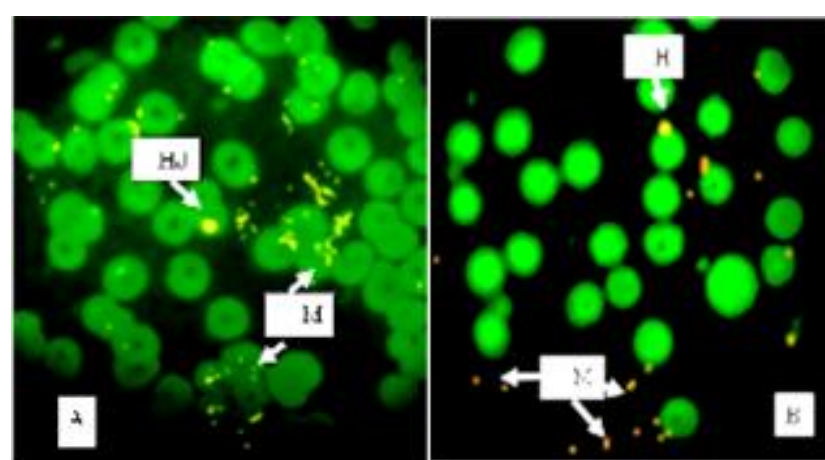

Figure 8(A, B): Blood smears from anemic calve with eperythrocytic haemomycoplasma organisms (M), Note that the Howell-Jolly bodies (HJ) in A and Heinz bodies $(\mathrm{H})$ in B, stain with acridine orange, under oil immersion $100 \mathrm{X}$.

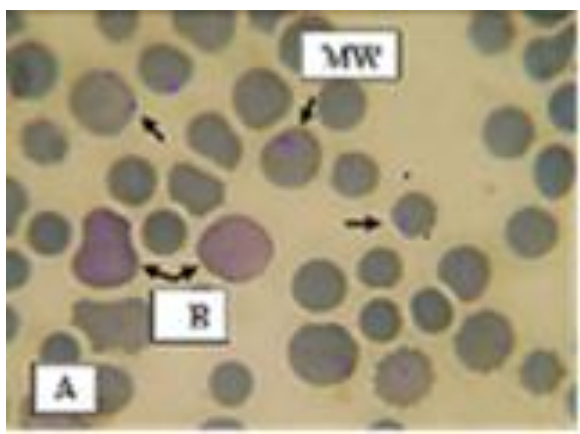

Figure 9(A): Numerous intensely stained Mycoplasma wenyonii (MW) can be observed on the surface of erythrocytes. Note the macrocytic cells with polychromasia (MP) and basophilic stippling (BS).

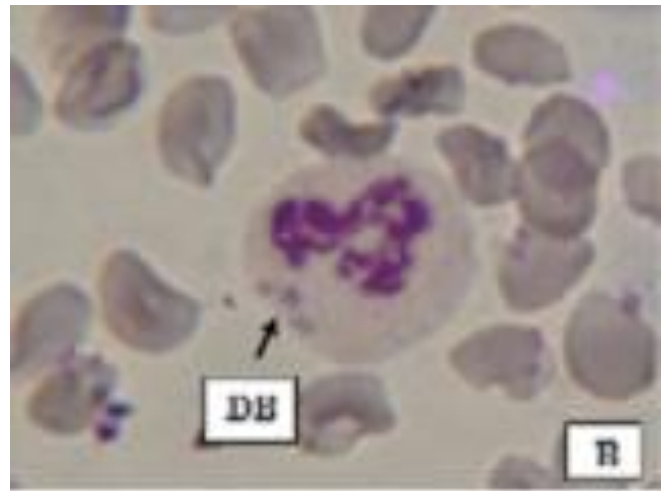

Figure 9(B): Mild toxic neutrophilia with cytoplasmic basophilia and Döhle bodies (DB). 160X, Wright's stain.

Table 3: Erythrocyte inclusions in blood smear of cattle which infected with hemomycoplasma positive and negative groups

\begin{tabular}{|c|c|c|c|c|}
\hline $\begin{array}{c}\text { Erythrocyte inclusions } \\
\text { (\%) }\end{array}$ & $\begin{array}{c}\text { Positive } \\
\text { cows } \\
(n=6)\end{array}$ & $\begin{array}{c}\text { Negative } \\
\text { cows } \\
(n=6)\end{array}$ & $\begin{array}{c}\text { Positive } \\
\text { calves } \\
(n=6)\end{array}$ & $\begin{array}{c}\text { Negative } \\
\text { calves } \\
(n=6)\end{array}$ \\
\hline Reticulocyte & $2 \%$ & 0 & $3 \%$ & 0 \\
\hline Nucleated RBC / 100WBC & 5 & 0 & 10 & 0 \\
\hline $\begin{array}{c}\text { Basophilic stippling/100 } \\
\text { Microscopic field }\end{array}$ & $\begin{array}{c}1-5 \\
(1+)\end{array}$ & 0 & $\begin{array}{c}1-5 \\
(1+)\end{array}$ & 0 \\
\hline $\begin{array}{c}\text { Heinz bodies / 100 } \\
\text { Microscopic field }\end{array}$ & $\begin{array}{c}(1-5 \\
(1+)\end{array}$ & 0 & $\begin{array}{c}5-10 \\
(2+)\end{array}$ & 0 \\
\hline Howell-Jolly bodies & $1-2$ & 0 & $1-2$ & 0 \\
/ 100 Microscopic field & $(1+)$ & & $(1+)$ & \\
\hline
\end{tabular}




\section{International Journal of Science and Research (IJSR) \\ ISSN (Online): 2319-7064}

Index Copernicus Value (2013): 6.14 | Impact Factor (2014): 5.611

Mycoplasma wenyonii (MW)-specific DNA was detected by PCR and Denaturing Gradient Gel Electrophoresis (DGGE) in blood samples of calves and dairy cows showing clinical signs. Although epi-erythrocytic organisms were seen on blood smears from all sampled cattle, only five samples (two cows and three calves) were PCR positive. Mycoplasma wenyonii was identified by PCR/DGGE in samples 1(Lane 6), 4 (Lane9), 5 (Lane10), 9 (Lane14) \& 10 (Lane15). According to $16 \mathrm{~S}$ rDNA PCR and DGGE an identical band was seen in all five samples which did match with bands of positive control samples( Lanes 3 and 19) of the known bovine mycoplasma controls; the control isolate of Mycoplasma wenyonii599. The samples 5(Lane 10) and 10(Lane 15) gave a strong high band on the DGGE whereas a weaker high band were seen in the samples 1(Lane 6), 4(Lane9) and 9(Lane 14). The samples 2,3,6,7, 8, 11, 12 had negative results. Unidentified multiple bands were also detected in samples 2, 3, 4, 7, 8, 9 \& 11. For those samples with unidentified bands we will need to see if sequencing gives any more information. Usually multiple bands do not give a good seqeunce, but we will have to see what we get. These bands were not consistent with $M$. wenyonii and had a low identity to a variety of Pseudomonas and Klebseila species on sequencing most likely due to contamination (Figure 10).

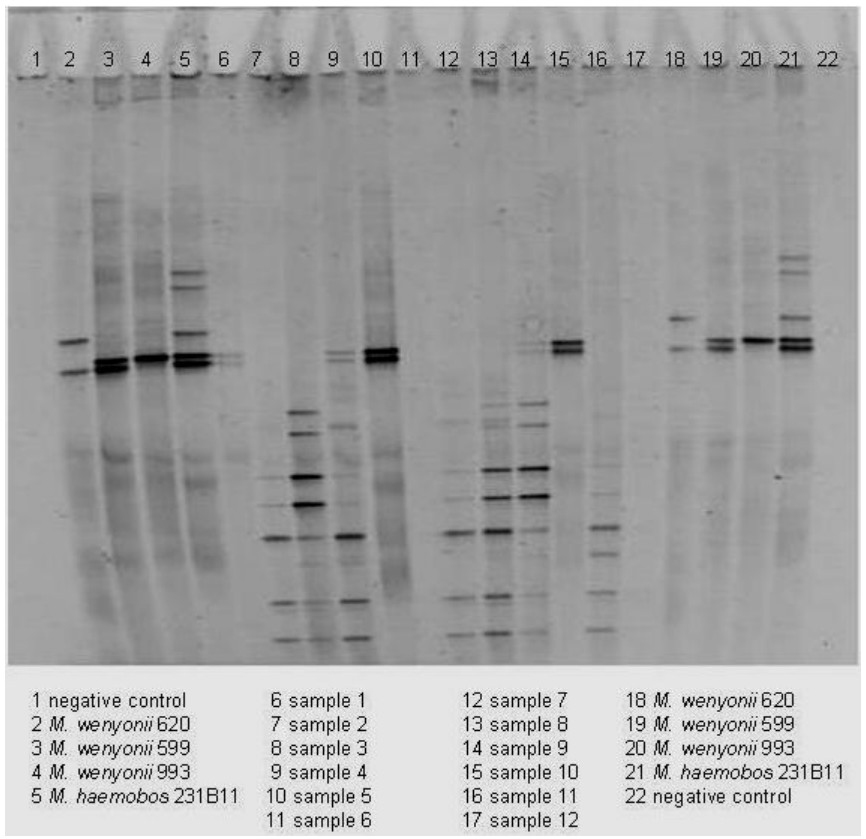

Figure 10: DGGE of cattle Hemotrophic Mycoplasmas.

Lanes: 1 and 22 Negative control; Positive control of Mycoplasma wenyonii 2 and $18 \mathrm{M}$. wenyonii 620, 3 and 19 $M$. wenyonii 599, 4 and $20 M$. wenyonii 993, 5 and $21 M$.

haemobos 231B11; Samples: Lane 6,9,10,14,15, $M$. wenyonii 599. Samples (1-6) are of calves and samples (7 12) from dairy cows.

\section{Discussion}

This study represents the first documented report of Mycoplasma wenyonii in cattle of Iraq. A combination of hind limb, udder or scrotal edema, pyrexia, in appetence and prefemoral lymphadenopathy is considered highly suggestive of $M$. wenyonii infection in cattle $[13,14]$. How a hemomycoplasma with a tropism for the erythrocyte membrane causes or contributes to clinical signs of hind limb and udder edema is not exactly clear at present. Based on biopsies of edematous skin, suggested that the edema might be caused by vasculitis, possibly an Arthus-type reaction with deposition of immune complexes in the vascular endothelium. Immune-mediated disease is a feature of Mycoplasma infections in other species and humans. This theory sounds plausible, although further work is required [15].

Mycoplasma wenyonii has been previously reported to cause clinical anemia in young or splenectomized cattle [16, 17]. Complete blood counts performed on hemomycoplasma infected cattle revealed macrocytic anemia and marked alterations in erythrocyte morphology, however, there was evidence on blood smears (such as reticulocytosis, polychromatic macrocytes, Howell-Jolly bodies, Heinz bodies and basophilic stippling) that anemia in most cattle with the haemomycoplasma organisms was strongly regenerative. The bacteria attached to the RBC membrane surface, which caused different levels of RBC deformation, increased membrane injury associated with various pathologic disorders which can result in increased phagocytosis of erythrocytes by macrophages. Lysis of erythrocytes within macrophages after phagocytosis is sometimes referred to as extravascular hemolysis. We suggest that intimate contact of hemmycoplasma organisms with RBCs leads to cell injury through immune-mediated, erythrophagocytosis and non-specific factors, which increase red cell fragility and may be the cause of anemia. Further work is needed to characterize the mechanism of anemia in cattle with $M$. wenyonii. A mild toxic change of some neutrophils is likely due to acute inflammation [18]. Mycoplasma wenyonii was first described in 2011 in Iraq using blood smear examination to the organism formerly known as Eperythrozoon wenyonii (Mycoplasma wenyonii) by [8]. The PCR/ DGGE were able to identify the presence of the bacteria, even in very small amounts. Only five samples were positive in PCR from total transmitted samples, however, most of the ill cows and calves had received extensive treatment with Oxy-tetracycline or Imidocarb in local clinics before the samples collection, which might have led to the underestimation of $M$. wenyonii infection in ill cattle. Samples 5 and 10 from cattle not treated gave a strong high band on the DGGE whereas a weaker high band and a much lower band were seen in samples 1, 4 and 9 from cattle treated previously with Oxytetracyclin and negative results with samples treated with imidocarb because hemomycoplasma blood loads can be reduced by application of these therapies $[19,20]$.

We also suggest that long storage of blood samples or DNA may have led to DNA degradation, and therefore, samples with a long history of storage may have appeared PCR negative by mistake. This may explain why several samples (2, 3, 6, 7, 8, 11 and 12) from 2011 reacted negative in the PCR (performed in 2012/2013) even though, the samples were positive in 2011, as determined by microscopy. Blood had been stored at $-20{ }^{\circ} \mathrm{C}$, but DNA can degrade due to repeated freezing and thawing. Blood samples, which were posted by DHL, had a long 'travel history' to the Veterinary

\section{Volume 5 Issue 2, February 2016}




\section{International Journal of Science and Research (IJSR) \\ ISSN (Online): 2319-7064}

Index Copernicus Value (2013): 6.14 | Impact Factor (2014): 5.611

Laboratory Agency (AHVLA), UK where they were processed. Taking this into account, the calculated blood loads in the samples with a longer storage or shipment history may have been too low or possibly PCR may have reacted negative in error. $M$. wenyonii 599 was thought to be a very serious infection of cattle. We need further studies about the epidemiology of $M$. wenyonii in cattle of Iraq to determine whether; $M$. wenyonii is the only hemomycoplasma present in Iraqi cattle or another species is the causative agent of the disease, if cattle is the only animal species that is affected with hemomycoplasma, and if $M$. wenyonii 599 is the only strain present or other strains play a role in the epidemiology of disease in cattle.

\section{Conclusions}

This is the first report of Mycoplasma wenyonii in calves, and dairy cows in Iraq based on molecular evidence. Further work is required in order to determine the true mechanism of anemia in Mycoplasma wenyonii infection of cattle as well as the epidemiology of disease in Iraq.

\section{References}

[1] Neimark H, Johansson K, Rikihisa Y, Tully JG. Proposal to transfer some members of the genera Haemobartonella and Eperythrozoon to the genus Mycoplasma with descriptions of 'Candidatus Mycoplasma haemofelis', 'Candidatus Mycoplasma haemomuris', 'Candidatus Mycoplasma. CVJ 52:10211022, 2001.

[2] Smith JA, Thrall MA, Smith JL, Salman MD, Ching SV, Collins JK. Eperythrozoon wenyonii infection in dairy cattle. J Am Vet Med Assoc 196: 1244-1250,1990 .

[3] Messick JB. Hemotrophic mycoplasmas (hemoplasmas): A review and new insights into pathogenic potential. Vet Clin Pathol 33:, 2-13,2004.

[4] Radostits OM, Gay CC. Hinchcliff, KW. Constable, P.D. Veterinary Medicine: A Textbook of the Diseases of Cattle, Horses, Sheep, Pigs, and Goats, 10th ed. pp.1154-1156, Philadelphia, Pennsylvania, Elsevier, USA, 2007.

[5] McAuliffe L, Ellis RJ, Ayling RD, Nicholas RA. Differentiation of Mycoplasma species by $16 \mathrm{~S}$ ribosomal DNA PCR and denaturing gradient gel electrophoresis fingerprinting. J Clin Microbiol, 41: 4844 - 4847, 2003.

[6] Strugnell B, McAuliffe,L. Mycoplasma wenyonii infection in cattle. In Pract, 34:146-154, 2012.

[7] McAuliffe L, Lawes J, Bell S, Barlow A, Ayling R, Nicholas RA. The detection of Mycoplasma (formerly Eperythrozoon) wenyonii by $16 \mathrm{~S}$ rDNA PCR and denaturing gradient gel electrophoresis. Vet Microb 117: 292-296, 2006.

[8] AL-Badrani BA , Rhaymah MSH. A clinical and diagnostic study of Mycoplasma wenyonii and Haemobartonella bovis infections in cattle of Mosul city, Iraq. Res Opin Anim Vet Sci 2: 27-30, 2012.

[9] Hu Z, Yin J, Shen K, Kang W, Qijun I. Outbreaks of Hemotrophic Mycoplasma Infections in China. Emerg Infec Dis 15: 1139 - 1140, 2009.
[10] Yuan CL, Yang ZB, Yao CB, Yang ZB, Zhu JG, Cui L, Yu F, Zhu NY, Yang XW, Hua XG. Prevalence study of Mycoplasma suis (Eperythrozoon suis) infection in swine and swine-farm workers in Shaghai, China. Am J Vet Res 70: 890-894, 2009.

[11] Harvey JW. Veterinary hematology: a diagnostic guide and color atlas. $1^{\text {st }}$ ed. pp.13-19, Saunders, an imprint of Elsevier Inc., 2012.

[12] Marchesi JR, SatoT, Weightman AJ, Martin TA, Fry JC, Hiom SJ, Wade WG. Design and evaluation of useful bacterium-specific PCR primers that amplify genes coding for bacterial 16S rRNA. Appl Environ Microbiol 64: 795-799, 1998.

[13] Montes AJ, Wolfe DF, Welles EG, Tyler JW, Tepe E. Infertility associated with Eperythrozoon wenyonii infection in a bull. J Am Vet Med Assoc 204: 261-263, 1994.

[14] Scott R. Distal hind limb and udder oedema of dairy cattle associated with an unidentified haemotrophic bacterium with microscopic characteristics of Mycoplasma (formerly Eperythrozoon) wenyonii). Cattle Pract 16: 50-53, 2008.

[15] Strugnell BW, McAuliffe L, Longmire K, Ellis- Iverson J. Mycoplasma wenyonii associated with clinical signs in milking dairy cows after herd-wide bluetongue vaccination. Cattle Pract 19: 75-81, 2010.

[16] Genova SG, Streeter RN, Velguth KE, Snider TA, Kocan KM, Simpson KM. Severe anemia associated with Mycoplasma wenyonii infection in a mature cow. Can Vet J 52: 1018-1021, 2011.

[17] Al-Abadi BH, Al-Badrani BA. Cattle blood analyses for parasitic infestation in Mosul, Iraq. Res Opin Anim Vet Sci 2 535-542, 2012.

[18] Crosse P1, Ayling R, Whitehead C, Szladovits B, English K, Bradley D, Solano-Gallego L. First detection of 'Candidatus Mycoplasma haemolamae' infection in alpacas in England. Vet Rec 17: 71- 72, 2012 .

[19]Hung AL. Chemotherapeutic efficacy of imidocarb dipropionate on experimental Eperythrozoon ovis infection in sheep. Trop Anim Health Prod 18:97-102 , 1986.

[20] Yan Z, Liu J, Chen T, Cheng Z, Guo H, Wang Z, Wang Y. Treatment of Mycoplasma wenyonii Infection in Cows with Imidocarb Dipropionate Injectioncupuncture. J Acupunct Meridian Stud 1: 143-148, 2008 . 